\title{
What do we really know? A meta-analysis of studies into public responses to wind energy
}

\author{
Ian D. Bishop ${ }^{1, *}$ \\ ${ }^{1}$ University of Melbourne, Melbourne, Australia \\ * Corresponding author. Tel: +61 383444180, Fax: +61 393472916, E-mail: i.bishop@unimelb.edu.au
}

\begin{abstract}
There have now been many studies about the public response to wind energy infrastructure. This includes at least 31 papers already published in 2010. There remains however a large gap between the knowledge required for effective planning and the agreed understanding of visual and other impact levels, and the influence of planning and communication processes There is only limited agreement on some basic impact variables: numbers of turbines, amelioration with distance, role of design and so forth. There is no consensus on what methods should be used to assess acceptability or to design for acceptable outcomes. This means that, in many countries, there is no societal consensus about the acceptability of wide spread deployment of wind energy systems. This paper reviews recent studies in environmental, especially visual, impact and other aspects of the process that shape public response. These deal with issues and measures including both local and regional impacts, willingness-to-pay, validity of visual simulations and the use of virtual environments in design. The response of any individual and, cumulatively, of the community is a combination of affective and cognitive factors. Both are complex in character. Affective response involves primarily aesthetic appreciation but may be influenced by deep-seated philosophical attitudes to renewable energy in the context of global environmental issues. Cognitive responses overlay with the affective response in relation to global issues but also draw heavily on local factors of noise concerns, tourism effects and health issues. Cognitive responses are also dependent on personal circumstance and experiences and perceptions of the reasonableness of the planning process. These different aspects may be applied independently to infrastructure design, planning and evaluation but are often combined inappropriately in multi-factorial studies. A diversity of approaches in the literature are analyzed for their capacity to contribute to effective discrimination of the factors behind public responses to wind farm developments, to agreement on the key elements affecting local responses, and preferred approaches to planning and design. A combination of such meta-analysis and computational innovation in mapping and visualisation may provide the opportunity for integration of these advances in knowledge such that a systematic, objective, comprehensive and acceptable approach to wind energy infrastructure planning and design is feasible and achievable.
\end{abstract}

Keywords: Wind energy, Visual impact, Affective response, Cognitive response

\section{Introduction}

There has recently been a very rapid expansion of the literature on public responses to wind energy development and the visual landscape effects in particular. Between 2000 and 2006 there were 2-3 papers per year, in 2007 this jumped to 10, in 2009 to 15 and in 2010 over 30 papers were published on the topic. Some of these deal with aesthetic theory, some with impact mapping, some with experiments seeking to determine key impact variables and their relative importance, others deal with specific wind farm developments and the impact mapping, often linked to public consultation, which went with them. Given this surge of interest, provoked by the rapid expansion of the wind energy industry, it is time to ask what have we collectively learned from this research and how it makes for better planning.

While there is a high cross citation rate amongst these papers, there is also a wide diversity of approaches and research questions which means that there are as yet few definitive answers. The first stage of analysis of these contributions must therefore be to determine the research questions being asked and their relationship to each other. Key topics are:

- development of better tools or procedures for public engagement early in the planning process [1-5] 
- understanding of relative significance of key design variables such as distance, contrast, colour, movement [6-8], number of turbines [9-11], size of turbines [10, 12] whether on-shore or off-shore [13] and the existing quality of the host landscape [14]

- understanding of non-design variables such as conservation value of location or the planning process $[15,16]$, broad social attitudes to wind energy $[17,18]$ or behaviour (e.g. recreation) when exposed to wind energy facilities $[19,20]$

- more systematic analysis tools which respect multiple criteria in either site selection [21-25], impact assessment [8, 11, 26-28], historical changes in the landscape [29] or regional or national level impacts [30]

- responses to visual simulations [31]

- use of interactive virtual environments to facilitate interactive design [32]

- changing attitudes as a result of familiarity [16, 33]

- deep convictions about nature, landscapes and seascapes [34] and cultural ecosystem services [35]

- understanding the relationships between stakeholders in environmental conflicts [36]

- willingness-to-pay studies encompassing some of the other variables (such as distance) [13, 37-39]

- $\quad$ project evaluations including environmental externalities [40, 41]

- the NIMBY effect - or not? [18, 42-46]

This review will focus on just a small section of this wide range. That section is the attempt to establish some firm knowledge about how various design and planning variables contribute to expectations and responses to wind farm development. The analysis considers the variables in terms of the provoked affective and cognitive responses [47] since there are clear indications that both are at play in the public response. There is also a distinction to be made between responses to simulated wind energy developments, responses to proposed developments and responses to completed projects [16, 33]. It should also be noted that most studies consider several aspects of impact and response, in the list above and in the Tables below I have tended to focus on my perception of the main findings in each.

\section{Findings from the literature}

\subsection{Affective Response to Wind Energy}

As we experience the landscape we form impressions - such as beautiful or inspiring or unpleasant - without be conscious of any thinking behind those impressions. These responses have a high level of commonality within cultures and, in some respects, between cultures. They are largely unaffected by personal experiences, even familiarity with the landscape has been shown to have limited influence [48]. These apparently innate impressions are referred to as affective responses and have been attributed to evolutionary influences by some authors [49]. Because affective responses are relatively consistent across the population, we are in position to built a body of knowledge about typical responses and use these in spatially explicit landscape assessment and impact studies.

In the case of responses to wind energy infrastructure, we can consider our perceptions of the aesthetics of the developments as an affective response. Something we find intrudes on our enjoyment of landscape or something that adds elegance and interest to the view. Some people may have a positive response in certain landscape types and a negative response in a different landscape type, or the response may be influenced by the layout of the wind farm relative to the landscape, the number of turbines, their distance and so forth. However, we can expect similar sets of responses in different populations and similar dominant response types 
allowing development of an empirical framework for impact estimation. As mentioned, the key variables have been analyzed in a number of papers [6-13]. Some of the key findings are summarised in Table 1. These are separated into effects of on-shore and offshore installations, as there is limited comparative work. A review of related work [13] concluded that there was less impact from off-shore installation (reflected in greater willingness-to-pay to adopt that option) but the relative impacts of off- and on-shore infrastructure are not yet well defined and the preference for offshore is disputed in at least one recent review [50].

Studies in affective response typically use scenic beauty, visual quality or a similar phrase as a key reported measure - with some examples of willingness-to-pay and choice experiments. Several of the papers studied multiple variables but disentangling these is sometimes difficult. In addition, there are some clear disagreements in findings in several places - including in relation to important considerations like distance and size. Some studies that considered the size of wind farms (numbers of turbines) did so in the context of fixed total power output. In this situation mixed results were reported [12] with some communities preferring more distributed production while other saw benefit in greater concentration. However, this is more of a reasoned factor than a purely aesthetic one and leads us into the next section.

Table 1. Some key finding relating to aesthetic responses to wind energy infrastructure

\begin{tabular}{|c|c|c|}
\hline Variable Increasing & On-Shore Impact & Off-shore Impact \\
\hline \multirow[t]{2}{*}{ Distance } & - linear decline to at least $12 \mathrm{~km} \mathrm{[6]}$ & - linear decline to $\sim 12 \mathrm{~km} \mathrm{[7]}$ \\
\hline & - limited distance effect [14] & - decline with distance [38] \\
\hline \multirow[t]{3}{*}{ Number of turbines } & $\begin{array}{l}\text { - increase with number, size and } \\
\text { proximity until turbines occupy 15\% } \\
\text { of view, then constant [8] }\end{array}$ & no known studies \\
\hline & $\begin{array}{l}\text { - impact proportional to number of } \\
\text { windmills [10] }\end{array}$ & \\
\hline & $\begin{array}{l}\text { - between } 2 \text { and } 8 \text { turbines best } \\
\text { accepted [9] }\end{array}$ & \\
\hline \multirow[t]{2}{*}{ Colour/contrast } & - increase with contrast $[6,7]$ & - increase with contrast [7] \\
\hline & $\begin{array}{l}\text { - increase to } 1563 \text { CIELAB points } \\
\text { then constant [8] }\end{array}$ & \\
\hline \multirow[t]{3}{*}{ Size of turbines } & $\begin{array}{l}\text {-one 5MW turbine has more impact } \\
\text { than same from smaller units [10] }\end{array}$ & no known studies \\
\hline & - least important attribute [12] & \\
\hline & $\begin{array}{l}\text { - smaller turbines require less } \\
\text { compensation [15] }\end{array}$ & \\
\hline Movement & no known studies & $\begin{array}{l}\text { - less when blades moving } \\
\text { especially at low distances [7] }\end{array}$ \\
\hline Visual complexity & $\begin{array}{l}\text { - fractality introduced by [8], } \\
\text { simpler structures preferred }\end{array}$ & no known studies \\
\hline Continuity & $\begin{array}{l}\text { - bumps in outline envelope not } \\
\text { preferred [8] }\end{array}$ & no known studies \\
\hline Host landscape & $\begin{array}{l}\text { - effect is negative on landscapes of } \\
\text { higher scenic quality but a positive } \\
\text { on landscapes of lower quality [14] }\end{array}$ & $\begin{array}{l}\text { - greater distance offshore } \\
\text { preferred [38] }\end{array}$ \\
\hline
\end{tabular}




\subsection{Cognitive Response to Wind Energy}

It has been argued that the more visceral affective response ('the heart') is indeed conditioned by a rapid evolution driven cognitive response ('the head'). Whatever the truth of this, there are clearly a number of variables in human responses to wind turbines that require more sustained or deeper consideration than the aesthetic, or are dependent on knowledge or experience, and these are generally referred to as the cognitive factors. These may include specifically beliefs about nature, concerns about real estate values and trust in the planning process. Table 2 seeks to summarise findings on issues of this kind. Again, there are studies that were conducted in relation to on-shore installations and others where the focus was offshore, but these are not separated explicitly in this Table. Among the differences is the noise issue (which is in part aesthetic but of more sustained character and believed by some to induce specific negative health impacts hence applied with other cognitive factors here) that applies almost exclusively to on-shore facilities. The second is an argument, recently summarised [50], that off-shore turbines turn quintessentially natural [34] and often sublime sea or ocean views into industrial landscapes. On-shore facilities, on the other hand, are typically in locations long altered by human activities in the form of agricultural and transportation infrastructure.

Studies involving primarily cognitive variables use a range of measures that seem very similar but this similarity could be misleading. Acceptability is not the same as willingness-to-accept compensation, for example. General 'attitude' to wind infrastructure may be different again because of a range of factors reviewed in the environmental economics literature [51].

Table 2. Some key finding relating to cognitive responses to wind energy infrastructure. The variable of column 1 is measured by the measure in column 2. Column 3 indicates the way in which the response measure depends on the variable.

\begin{tabular}{|c|c|c|}
\hline Variable & Response Measure & Findings \\
\hline protected site [15] & $\begin{array}{l}\text { willingness to accept } \\
\text { compensation }\end{array}$ & avoid protected sites \\
\hline $\begin{array}{l}\text { planning with local } \\
\text { representatives [15] }\end{array}$ & $\begin{array}{l}\text { willingness to accept } \\
\text { compensation }\end{array}$ & engage locally \\
\hline $\begin{array}{l}\text { prior experience with off- } \\
\text { shore wind farms [16] }\end{array}$ & attitude to visual impacts & $\begin{array}{l}\text { experience with more } \\
\text { distance farm leads to more } \\
\text { positive attitude }\end{array}$ \\
\hline $\begin{array}{l}\text { local electricity shortages } \\
\text { [17] }\end{array}$ & acceptability & $\begin{array}{l}\text { local needs on island } \\
\text { suggested as positive } \\
\text { contributor }\end{array}$ \\
\hline $\begin{array}{l}\text { small scale introduction } \\
\text { [17] }\end{array}$ & acceptability & $\begin{array}{l}\text { suggested as positive } \\
\text { contributor }\end{array}$ \\
\hline $\begin{array}{l}\text { open-minded, international } \\
\text { contacts [17] }\end{array}$ & acceptability & $\begin{array}{l}\text { suggested as positive } \\
\text { contributor }\end{array}$ \\
\hline $\begin{array}{l}\text { the developers, poor local } \\
\text { communications }[18,44]\end{array}$ & acceptability & $\begin{array}{l}\text { suggested as negative } \\
\text { contributor }\end{array}$ \\
\hline occasional beach use [19] & $\begin{array}{l}\text { stated attitude to offshore } \\
\text { infrastructure }\end{array}$ & more positive attitude \\
\hline $\begin{array}{c}\text { regular year-round beach } \\
\text { use [19] }\end{array}$ & $\begin{array}{l}\text { stated attitude to offshore } \\
\text { infrastructure }\end{array}$ & more negative attitude \\
\hline living with wind farm [33] & $\begin{array}{l}\text { range of beliefs on benefits, } \\
\text { visual qualities, energy security }\end{array}$ & $\begin{array}{l}\text { more awareness of benefits, } \\
\text { greater acceptance }\end{array}$ \\
\hline
\end{tabular}




\section{Discussion and Conclusion}

The research methods used in trying to increase our understanding of the many variables introduced in the literature include attitude surveys, observational methods, willingness-topay (or be paid) studies, choice experiments and so forth. The entities on which people are asked to comment include real wind farms (post construction), hypothetical wind farms, visually simulated wind farms and abstract concepts in renewable energy. Nearly all the reported results are the outcome of research by professional people and have been peer reviewed.

Despite the breadth and depth of our investigations we do not yet know all the answers. We cannot yet predict what the response to a particular wind farm proposal will be (although many people would be willing to guess), if compensation is a possibility we do not know how to quantify it or spatially distribute it. We don't know what distribution of turbines across the landscape (to meet specific power needs) will have the least visual impact: should we have bigger but fewer turbines? Bigger but fewer farms?

Yet, some points are fairly clear:

- aesthetic impacts are less the further the viewer is from the turbines (although we have no clear idea of the shape of the distance-impact curve)

- contrast with the surroundings and background should be low

- farms should not be located in highly valued landscapes

- the distribution and design of the turbines should have regard for aesthetic factors such as complexity and continuity

- protected sites should be avoided

- less dissent arises through "involvement of the local population in the siting procedure, transparent planning processes, and a high information level" [18].

- familiarity with existing small scale projects is likely to increase later acceptance of further projects

A number of the studies mentioned were multi-factorial and sought to determine the relative significance of a range of contributing variables. If we accept the premise that responses to wind turbines are of two distinct kinds, one largely independent of culture, education, wealth and personal experience (the affective) and one heavily dependent on the circumstances of an affected community, then it is probably unwise to be mixing these together in our research studies. We need to know more about both, but putting both together into a single study can muddy the waters and fail to give a clear answer on either variable type. Once we have deeper knowledge about the aesthetics, for example, then we might combine this with other factors in a more comprehensive study.

In addition, and briefly mentioned above, there have been important attempts to create geographic information system based tools for prediction of visual, and other, impacts [52]. These have a significant potential role to play in relation to initial site selection and design and should complement systems based on wind potential mapping and other engineering factors. Finally, these can be supplemented but interactive collaborative design systems, such as [32], which can help to create the knowledge, participation and sense of involvement which are just as critical to the outcome as the planning and design itself. 


\section{References}

[1] G. Higgs, R. Berry, D. Kidner and M. Langford, Using IT approaches to promote public participation in renewable energy planning: Prospects and challenges, Land Use Policy, 25, 2008, pp.596-607.

[2] A. Simao, P.J. Densham and M. Haklay, Web-based GIS for collaborative planning and public participation: An application to the strategic planning of wind farm sites, Journal of Environmental Management, 90, 2008, pp.2027-2040.

[3] M. Portman, Involving the public in the impact assessment of offshore renewable energy facilities, Marine Policy, 33, 2009, pp.332.

[4] G. Munda and G. Gamboa, The problem of windfarm location: A social multi-criteria evaluation framework, Energy Policy, 35, 2007, pp.1564-1583.

[5] D. Robb, Thoughtful planning reaps widespread support for New York wind project, Power Engineering, 107, 2003, pp.36-40.

[6] I.D. Bishop, Determination of thresholds of visual impact: the case of wind turbines, Environment and Planning B: Planning and Design, 29, 2002, pp.707-718.

[7] I.D. Bishop and D.R. Miller, Visual assessment of off-shore wind turbines: The influence of distance, contrast, movement and social variables, Renewable Energy, 32, 2007, pp.814-831.

[8] A.D. Torres-Sibille, V.A. Cloquell-Ballester, V.A. Cloquell-Ballester and R. Darton, Development and validation of a multicriteria indicator for the assessment of objective aesthetic impact of wind farms, Renewable \& Sustainable Energy Reviews, 13, 2009, pp.40-55.

[9] N. Daugarrd, Acceptability Study of Wind Power in Denmark, Energy Centre Denmark, Copenhagen, 1997.

[10]T. Tsoutsos, A. Tsouchlaraki, M. Tsiropoulos and M. Serpetsidakis, Visual impact evaluation of a wind park in a Greek island, Applied Energy, 86, 2009, pp.546-553.

[11]T. Tsoutsos, A. Tsouchlaraki, M. Tsiropoulos and J. Kaldellis, Visual impact evaluation methods of wind parks: Application for a Greek Island, Wind Engineering, 33, 2009, pp.83-92.

[12]J. Meyerhoff, C. Ohl and V. Hartje, Landscape externalities from onshore wind power, Energy Policy, 38, 2010, pp.82-92.

[13] J. Ladenburg, Stated public preferences for on-land and offshore wind power generation A review, Wind Energy, 12, 2009, pp.171-181.

[14]A. Lothian, Scenic perceptions of the visual effects of wind farms on South Australian landscapes, Geographical Research, 46, 2008, pp.196-207.

[15] A. Dimitropoulos and A. Kontoleon, Assessing the determinants of local acceptability of wind-farm investment: A choice experiment in the Greek Aegean Islands, Energy Policy, 37, 2009, pp.1842-1854.

[16]J. Ladenburg, Visual impact assessment of offshore wind farms and prior experience, Applied Energy, 86, 2009, pp.380-387.

[17]J.K. Kaldellis, Social attitude towards wind energy applictions in Greece, Energy Policy, 2003, pp.8. 
[18]S. Krohn and S. Damborg, On Public Attitudes Towards Wind Power, Renewable Energy, 16, 1999, pp.954-960.

[19] J. Ladenburg, Attitudes towards offshore wind farms-The role of beach visits on attitude and demographic and attitude relations, Energy Policy, 38, 2010, pp.1297-1304.

[20] M.B. Lilley, J. Firestone and W. Kempton, The effect of wind power installations on coastal tourism, Energies, 3, 2010, pp.1-22.

[21] S.M.J. Baban and T. Parry, Developing and applying a GIS-assisted approach to locating wind farms in the UK, Renewable Energy, 24, 2000, pp.59-71.

[22]I.J. Ramirez-Rosado, E. Garcia-Garrido, L.A. Fernancez-Jimenez, P.J. ZorzanoSantamaria, C. Monteiro and V. Miranda, Promotion of new wind farms based on a decision support system, Renewable Energy, 33, 2007, pp.558-566.

[23]P. Lejeune and C. Feltz, Development of a decision support system for setting up a wind energy policy across the Walloon Region (southern Belgium), Renewable Energy, In Press, Corrected Proof, 2010,

[24] M. Petri and S. Lombardo, Renewable energy sources: The case of wind farms analysis, in O. Gervasi and B. Murgante (ed), Computational Science and Its Applications - Iccsa 2008, Pt 1, Proceedings, 2008, pp.111-125

[25]L.I. Tegou, H. Polatidis and D.A. Haralambopoulos, Environmental management framework for wind farm siting: Methodology and case study, Journal of Environmental Management, 91, 2010, pp.2134-2147.

[26]B. Alvarez-Farizo and N. Hanley, Using conjoint analysis to quantify public preferences over the environmental impacts of wind farms. An example from Spain, Energy Policy, 30, 2002, pp.107-116.

[27] J.P. Hurtado, J. Fernandez, J.L. Parrondo and E. Blanco, Spanish method of visual impact evaluation in wind farms, Renewable \& Sustainable Energy Reviews, 8, 2004, pp.483491.

[28]B. Moller, Changing wind-power landscapes: regional assessment of visual impact on land use and population in Northern Jutland, Denmark, Applied Energy, 83, 2006, pp.477-494.

[29]B. Moller, Spatial analyses of emerging and fading wind energy landscapes in Denmark, Land Use Policy, 27, 2010, pp.233-241.

[30] M. Rodrigues, C. Montanes and N. Fueyo, A method for the assessment of the visual impact caused by the large-scale deployment of renewable-energy facilities, Environmental Impact Assessment Review, 30, 2010, pp.240-246.

[31] R. Phadke, Steel forests or smoke stacks: The politics of visualisation in the Cape Wind controversy, Environmental Politics, 19, 2010, pp.1-20.

[32] I.D. Bishop and C. Stock, Using collaborative virtual environments to plan wind energy installations, Renewable Energy, 35, 2010, pp.2348-2355.

[33]D.C. Eltham, G.P. Harrison and S.J. Allen, Change in public attitudes towards a Cornish wind farm: Implications for planning, Energy Policy, 36, 2008, pp.23-33.

[34] K. Gee, Offshore wind power development as affected by seascape values on the German North Sea coast, Land Use Policy, 27, 2010, pp.185-194. 
[35]K. Gee and B. Burkhard, Cultural ecosystem services in the context of offshore wind farming: A case study from the west coast of Schleswig-Holstein, Ecological Complexity, 7, 2010, pp.349-358.

[36] M.I. Gonzalez and B. Estevez, Participation, communication and negotiation in environmental conflicts: Offshore wind energy in the Trafalgar Sea area, Arbor-Ciencia Pensamiento Y Cultura, 181, 2005, pp.377-392.

[37]P.A. Groothuis, J.D. Groothuis and J.C. Whitehead, Green vs. green: Measuring the compensation required to site electrical generation windmills in a viewshed, Energy Policy, 36, 2008, pp.1545.

[38] J. Ladenburg and A. Dubgaard, Willingness to pay for reduced visual disamenities from offshore wind farms in Denmark, Energy Policy, 35, 2007, pp.4059-4071.

[39] G. Riddington, D. McArthur, T. Harrison and H. Gibson, Assessing the Economic Impact of Wind Farms on Tourism in Scotland: GIS, Surveys and Policy Outcomes, International Journal of Tourism Research, 12, 2010, pp.237-252.

[40] D. Moran and C. Sherrington, An economic assessment of windfarm power generation in Scotland including externalities, Energy Policy, 35, 2007, pp.2811-2825.

[41] J. Munksgaard and A. Larsen, Socio-economic assessment of wind power-lessons from Denmark, Energy Policy, 26, 1998, pp.85-93.

[42]C.R. Jones and J.R. Eiser, Understanding 'local' opposition to wind development in the UK: How big is a backyard?, Energy Policy, 38, 2010, pp.3106-3117.

[43]W. Roper and N. Campeau, Renewable energy production issues with the Cape Cod offshore wind energy programme, International Journal of Environmental Technology and Management, 6, 2006, pp.405-420.

[44]M. Wolsink, Wind power and the NIMBY-myth: institutional capacity and the limited significance of public support, Renewable Energy, 21, 2000, pp.49-64.

[45] M. Wolsink, Planning of renewables schemes: Deliberative and fair decision-making on landscape issues instead of reproachful accusations of non-cooperation, Energy Policy, 35, 2007, pp.2692-2704.

[46]M. Wolsink, Wind power implementation: The nature of public attitudes: Equity and fairness instead of 'backyard motives', Renewable \& Sustainable Energy Reviews, 11, 2007, pp.1188-1207.

[47]S. Kaplan, Aestethics, affect and cognition: Environmental preference from an evolutionary perspective, Environment and Behavior, 19, 1987, pp.3 - 32.

[48]J.D. Wellman and G.J. Buyhoff, Effects of Regional Familiarity on Landscape Preferences, Env. and Behav., 1980, pp.105-110.

[49] J.H. Appleton, The Experience of Landscape, John Wiley, 1975.

[50]C. Haggett, Understanding public responses to offshore wind power, Energy Policy, 2011,

[51]A.M. Freeman, The measurement of environmental and resource values: theory and methods, Resources for the Future, 2nd edition, 2003.

[52]M. Rodrigues, C. Montañés and N. Fueyo, A method for the assessment of the visual impact caused by the large-scale deployment of renewable-energy facilities, Environmental Impact Assessment Review, 30, 2010, pp.240-246. 